Published in final edited form as:

Obstet Gynecol. 2014 October ; 124(4): 838-839. doi:10.1097/AOG.0000000000000486.

\title{
In Reply
}

\author{
Naomi K. Tepper, MD, MPH, \\ Division of Reproductive Health, National Center for Chronic Disease Prevention and Health \\ Promotion, Centers for Disease Control and Prevention, Atlanta, Georgia
}

\section{Sheree L. Boulet, DrPH, MPH,}

Division of Reproductive Health, National Center for Chronic Disease Prevention and Health Promotion, Centers for Disease Control and Prevention, Atlanta, Georgia

\section{Maura K. Whiteman, PhD,}

Division of Reproductive Health, National Center for Chronic Disease Prevention and Health Promotion, Centers for Disease Control and Prevention, Atlanta, Georgia

\section{Michael Monsour, PhD,}

Division of Reproductive Health, National Center for Chronic Disease Prevention and Health Promotion, Centers for Disease Control and Prevention, Atlanta, Georgia

\section{Polly A. Marchbanks, PhD,}

Division of Reproductive Health, National Center for Chronic Disease Prevention and Health Promotion, Centers for Disease Control and Prevention, Atlanta, Georgia

\section{W. Craig Hooper, PhD, and}

Division of Blood Disorders, National Center on Birth Defects and Developmental Disabilities, Centers for Disease Control and Prevention, Atlanta, Georgia

\section{Kathryn M. Curtis, PhD}

Division of Reproductive Health, National Center for Chronic Disease Prevention and Health Promotion, Centers for Disease Control and Prevention, Atlanta, Georgia

\begin{abstract}
We thank Drs. Gizzo, Nardelli, and Noventa for their interest in our article, and their comments give us an opportunity to elaborate on several aspects of our analysis. ${ }^{1}$ The main objective of our analysis was to calculate the incidence of venous thromboembolism among postpartum women through postpartum week 12 and to examine how certain factors affect that risk according to timing postpartum. Our objectives did not include examining when or how to apply thromboprophylaxis. We agree that the interpretation of epidemiologic studies should consider relevant limitations. In our article, we acknowledge a number of limitations, including concerns about the accuracy and completeness of claims data and the inability to account for the influence of associated factors such as peripartum pharmacologic thromboprophylaxis and non-pharmacologic thromboprophylaxis. Despite limitations, the results from our work add to the field of knowledge on postpartum venous
\end{abstract}

Financial Disclosure: The authors did not report any potential conflicts of interest.

The findings and conclusions in this article are those of the authors and do not necessarily represent the official position of the Centers for Disease Control and Prevention. 
thromboembolism. Venous thromboembolic disease remains an important cause of peripartum morbidity and mortality, ${ }^{2,3}$ and our findings highlight the fact that the risk extends into the postpartum period, particularly among women with certain risk factors. We hope our article will help to increase awareness among clinicians and stimulate further study on this issue, including implications for postpartum thromboprophylaxis.

\section{References}

1. Tepper NK, Boulet SL, Whiteman MK, Monsour M, Marchbanks PA, Hooper WC, et al. Postpartum venous thromboembolism: incidence and risk factors. Obstet Gynecol. 2014; 123:987-96. [PubMed: 24785851]

2. Callaghan WM. Overview of maternal mortality in the United States. Semin Perinatol. 2012; 36:26. [PubMed: 22280858]

3. Callaghan WM, Creanga AA, Kuklina EV. Severe maternal morbidity among delivery and postpartum hospitalizations in the United States. Obstet Gynecol. 2012; 120:1029-36. [PubMed: 23090519] 